\title{
Frovatriptan Succinate
}

National Cancer Institute

\section{Source}

National Cancer Institute. Frovatriptan Succinate. NCI Thesaurus. Code C47544.

The succinate salt form of frovatriptan, a synthetic triptan with serotonin $(5-\mathrm{HT})$

receptor agonist activity. Frovatriptan succinate binds selectively and with high affinity to

5-HT 1B and presynaptic 5-HT 1D receptors in the extracerebral and intracranial arteries.

This leads to an inhibition of serotonin activity and results in vasoconstriction of the

painfully dilated blood vessels during migraine attack. Frovatriptan succinate is indicated

for the acute treatment of migraine. ( $\mathrm{NCI05)}$ 